\title{
A new extracellular protein of Pseudomonas aeruginosa PA103 regulated by regA
}

\author{
Christiane Wolz, ${ }^{1}$ Rainer Lehmann, ${ }^{1}$ Mike L. Vasil, ${ }^{2}$ Rainer Bischoff ${ }^{3}$ \\ and Gerd Döring ${ }^{1}$
}

Author for correspondence: Christiane W'olz. Tel: +497071 294662. Fax: + 497071293011.

\footnotetext{
1 Department of General and Environmental Hygiene, Hygiene Institute, University of Tübingen, Tübingen, Germany

2 Department of Microbiology and Immunology, University of Colorado, Health Sciences Center, Denver, Colorado 80262, USA

3 Transgene, Protein Analytical Group. Strasbourg, France
}

\begin{abstract}
The expression of exotoxin A (ExOA) from Pseudomonas aeruginosa is influenced by iron and is under the control of the regulatory gene regA. To test whether regA plays a role in the expression of other iron-regulated proteins a RegA- mutant was constructed by insertional mutagenesis. The polypeptide pattern of this mutant (PA103R) was compared with the parental strain (PA103) and a trans-complemented strain PA103R(PREX18) after growth of the strains in conditions containing low or high concentrations of iron. An ironregulated $42 \mathrm{kDa}$ protein (RRP) was identified and purified from the culture supernatant of PA103 and PA103R(PREX18) which was missing in PA103R. Database analysis of the $\mathbf{N}$-terminal sequence of this regA-regulated protein (RRP) revealed no similarity to other proteins. Preliminary investigations into the function of RRP revealed that it has no proteolytic or cytotoxic activity. Using two-dimensional electrophoretic analysis of whole cells, a technique which allowed separation of over 600 polypeptides, we were unable to identify any other iron-regulated protein whose expression was regulated by regA.
\end{abstract}

Keywords: Pseudomonas aeruginosa, $\operatorname{reg} A$, gene regulation, iron-regulated proteins

\section{INTRODUCTION}

Bacteria respond to environmental changes with coordinate gene expression (Miller et al., 1989) using different signals and gene regulators. Also, the synthesis of virulence factors in Pseudomonas aeruginosa is influenced by various growth parameters. For example, production of exotoxin A (ExoA), a major virulence factor, is repressed under high iron conditions (Bjorn et al., 1978) and depends on the regulatory genes $\operatorname{reg} A$ and $\operatorname{reg} B$, which are organized in an operon (Hedstrom et al., 1986; for review, see Wick et al., 1990). reg $A$ regulates ExoA in trans at the level of transcription (Frank \& Iglewski, 1988; Frank et al., 1989, Wick et al., 1990) by an unknown mechanism. There is no evidence for binding of the $\operatorname{reg} A$ gene product RegA to the upstream region of the ExoA gene tox A (Hamood \& Iglewski, 1990). Transcript accumulation of $\operatorname{reg} A$ itself is enhanced in low iron medium and precedes tox $A$ transcription and translation (Frank \& Iglewski, 1988; Hindahl et al., 1988). The transcription of $\operatorname{reg} A$ involves two promoters, $\mathrm{P} 1$ and $\mathrm{P} 2$. Only the $\mathrm{P} 2$ promoter is strongly iron-regulated (Storey et al., 1990, 1991).

Abbreviations: ExoA, exotoxin A; RRP, regA-regulated protein.
Iron not only regulates ExoA synthesis but also affects the expression of other secreted proteins (Bjorn et al., 1979), of proteins from the outer membrane and of secondary metabolites. These phenomena may be linked in $P$. aeruginosa to a common regulatory mechanism such as the regulation of iron-regulated proteins by Fur in Escherichia coli (Bagg \& Neilands, 1987; Hantke, 1984). Recently a protein, analogous to Fur, was detected in $P$. aeruginosa and the gene cloned and sequenced (Prince et al., 1991, 1993). Mutants producing altered Fur proteins were selected and these mutants constitutively produced siderophores and ExoA under high iron conditions that usually repressed their production (Prince et al., 1993). Introduction of the fur gene from $E$. coli in $P$. aeruginosa inhibited the transcription of $\operatorname{reg} A$ from the $\mathrm{P} 1$ promoter as well as ExoA synthesis (Prince et al., 1991). Interestingly, transcription of the iron-regulated P2 promoter of $\operatorname{reg} A$ was not regulated by fur.

$\operatorname{reg} A$ as well as $f u r$ are candidate genes as global regulators for iron-regulated proteins in $P$. aeruginosa. At present, besides ExoA no other protein has been shown to be regulated by $\operatorname{reg} A$. To investigate the role of $\operatorname{reg} A$ in this context we constructed a RegA-negative mutant PA103R and compared the protein expression of this strain with 
Table 1. Bacteria and plasmids used in this study

\begin{tabular}{|c|c|c|}
\hline Organism & Characteristics & Reference \\
\hline \multicolumn{3}{|l|}{ E. coli } \\
\hline S17-1 & $\begin{array}{l}\text { MM294 with RP4 2-Tc::Mu-Km::Tn7 } \\
\text { integrated into the chromosome }\end{array}$ & Simon et al. (1983) \\
\hline HB101 & $\operatorname{rec} A 13 \operatorname{bsdS} 20\left(\mathrm{r}_{\mathrm{B}}^{-}, \mathrm{m}_{\mathrm{B}}^{-}\right)$ & Sambrook et al. (1989) \\
\hline \multicolumn{3}{|l|}{ P. aeruginosa } \\
\hline PA103 & Prototroph & Liu (1966) \\
\hline PA103R & $\begin{array}{l}\text { PA103 with pBRMOB-RegA integrated } \\
\text { in } \operatorname{reg} A\end{array}$ & This study \\
\hline PA103R(pREX18) & PA103-R complemented with pREX18 & This study \\
\hline \multicolumn{3}{|l|}{ Plasmids } \\
\hline pSUP201-1 & bla $\mathrm{cml} \mathrm{mob}$ & Simon et al. (1983) \\
\hline pBRMOB & $\begin{array}{l}\text { pBR322 ligated with } 1.8 \mathrm{~kb} \text { Bam HI mob } \\
\text { fragment from pSUP201-1 }\end{array}$ & This study \\
\hline pBRMOB-RegA & $\begin{array}{l}\text { pBRMOB ligated with } 366 \text { bp SalI- SalI } \\
\text { fragment from pUCEE } 8.5\end{array}$ & This study \\
\hline pREX18 & bla $\mathrm{Sm}^{\mathrm{R}} \mathrm{Su}^{\mathrm{R}} \operatorname{reg} A$ & Vasil et al. (1989) \\
\hline pRK2013 & $\begin{array}{l}\text { Helper plasmid, RK2 transfer gene with } \\
\text { ColE1 replicon }\end{array}$ & Figurski \& Helinski (1979) \\
\hline
\end{tabular}

the parental strain PA103 and the regA-complemented strain PA103R(pREX18).

\section{METHODS}

Strains, plasmids and glassware. Strains and plasmids used in this study are listed in Table 1 . For all iron-restricted growth experiments the glassware was rinsed in $1 \mathrm{mM}$ EDTA overnight followed by one rinse with $0 \cdot 1 \mathrm{M} \mathrm{HCl}$ and six with distilled $\mathrm{H}_{2} \mathrm{O}$.

Construction of RegA mutant of PA103. For insertional mutagenesis the mobilization vector $\mathrm{pBRMOB}-\mathrm{Reg} A$ was constructed. A $1.9 \mathrm{~kb}$ Bam HI fragment carrying the recognition site of mobilization from pSUP201-1 (Simon et al., 1983) was isolated and cloned into the BamHI site of pBR322 resulting in pBRMOB. The internal $366 \mathrm{bp} \mathrm{SalI-SalI} \mathrm{fragment} \mathrm{(coding}$ amino acids 52-174) of the $\operatorname{reg} A$ gene was subsequently ligated with the Sall site of $\mathrm{pBRMOB}$ and transformed into $E$. coli strain S17-1 which carries the tra genes of the broad-host-range plasmid RP4 integrated in the chromosome (Simon et al., 1983). pBRMOB-RegA was then transferred from $E$. coli to $P$. aeruginosa in filter matings (Vasil et al., 1989). Transconjugants were selected on cetrimide agar plates (selective $P$. aeruginosa agar, Difco) containing carbenicillin $\left(500 \mu \mathrm{g} \mathrm{m}^{-1}\right)$. The plasmid pBRMOB-RegA is only replicated in $P$. aeruginosa when integrated into the chromosome by homologous recombination with $\operatorname{reg} A$. This was confirmed by Southern blot analysis of purified chromosomal DNA digested with $X b o I$ and hybridized with the internal 366 bp $S a l l$ fragment from the $\operatorname{reg} A$ coding region. DNA methods were performed according to Sambrook et al. (1989), or the instruction of the manufacturer of the detection kit (Boehringer Mannheim).

Complementation of the regA mutation in PA103R. For complementation of the chromosomal $\operatorname{reg} A$ mutation in trans the $\operatorname{reg} A$ gene was transferred into PA103R by triparental mating between the donor strain E. coli 294(pREX-18) (Vasil $e t$ al., 1989), the E. coli helper strain HB101(pRK2013) and the recipient $P$. aeruginosa PA103R. The plasmid pREX-18 contains the coding region of $\operatorname{reg} A$ integrated into $\mathrm{pLC} 18$ and fused with the broad-host-range vector RSF1010. Mating was carried out as described by Vasil et al. (1989). Colonies were picked and analysed by radioimmunoassay (Döring et al., 1985) and immunoblotting for ExoA synthesis. The trans-complemented strain was designated PA103R(pREX18).

Media and growth conditions. E. coli was grown in LuriaBertani medium (Sambrook et al. 1989) supplemented with the appropriate antibiotics $\left(100 \mu \mathrm{g}\right.$ ampicillin $\left.\mathrm{ml}^{-1}\right)$. P. aeruginosa was grown in chelated trypticase soy broth (cTSB) (Kadurugamuwa et al., 1987). Double-strength trypticase soy broth (Oxoid) was prepared in 0.51 batches and passed twice through a Chelex-100 column (Bio-Rad) (200 ml bed volume) and finally adjusted to 11 with the water eluate of the column. To the medium $1 \%(\mathrm{v} / \mathrm{v})$ glycerol, $8.5 \mu \mathrm{M} \mathrm{ZnSO}_{4}, 1.3 \mathrm{mM}$ $\mathrm{MgSO}_{4}$ and $140 \mu \mathrm{M} \mathrm{CaCl}_{2}$ was added and the $\mathrm{pH}$ was adjusted to 7.4 before autoclaving. The iron concentration in the medium was $125 \mu \mathrm{g}^{-1}$ as determined by atomic absorption. For ironsufficient growth conditions, $45 \mu \mathrm{M} \mathrm{FeSO}_{4}$ was added from a freshly prepared sterile filtered stock solution just before inoculation of the bacteria. Bacteria were inoculated in $25 \mathrm{ml}$ medium into 100 flasks at an initial $\mathrm{OD}_{480}$ of 0.01 from a $10 \mathrm{~h}$ culture in the same medium. The mutant PA103R was precultured with $1000 \mu \mathrm{g}$ carbenicillin $\mathrm{ml}^{-1}$, strain PA103R (pREX18) with carbenicillin and streptomycin $\left(1000 \mu \mathrm{g} \mathrm{ml}^{-1}\right.$ each). Growth was followed by measuring the $\mathrm{OD}_{480}$ at $1 \mathrm{~h}$ intervals. As a control for purity and genetic stability all strains were plated on TSB agar with and without carbenicillin or streptomycin $\left(1000 \mu \mathrm{g} \mathrm{ml}^{-1}\right)$ after growth.

Cells were harvested by centrifugation $(4300 \mathrm{~g}, 10 \mathrm{~min})$. The few remaining cells were removed by a second centrifugation of the culture supernatant fluid $(15000 \mathrm{~g}, 30 \mathrm{~min})$. Cells were suspended in $0.85 \mathrm{M} \mathrm{NaCl}$ supplemented with $15 \%$ glycerol $\left(1 \mathrm{ml}\right.$ per $10^{9}$ cells), and frozen in aliquots at $-80^{\circ} \mathrm{C}$ until use. Culture supernatant $(10 \mathrm{ml})$ was dialysed against 11 distilled $\mathrm{H}_{2} \mathrm{O}$ overnight and dried in a vacuum concentrator or stored in 
aliquots until use. For electrophoresis the concentrate was resolved in $1 \mathrm{ml}$ of sample buffer (Laemmli, 1970).

SDSPAGE and immunoblotting. Proteins were separated using polyacrylamide gels containing SDS (Laemmli, 1970) with $3 \%$ $\left(\mathrm{w} / \mathrm{N}^{\prime}\right)$ crosslinking monomer concentration (C) and $10 \%$ total monomer concentration ( $\mathrm{T})$. The gels were stained with colloidal Coomassie blue $G$ (Neuhoff et al., 1985) or with silver (Blum et al., 1987). For immunoblotting, proteins were transferred to nitrocellulose (Schleicher \& Schuell) using a semidry blotting system (Millipore). Two different rabbit antibody preparations against ExoA served as primary antibody (Döring et al., 1985; Bourdenet et al., 1990). Immunoblots were developed with peroxidase-conjugated secondary antibodies (Dako-Diagnostika) in combination with chemoluminescence according to the manufacturer (Amersham Buchler).

Two-dimensional electrophoresis. This was performed on a horizontal system (Multiphore, Pharmacia) with an immobilized $\mathrm{pH}$ gradient in the first dimension and SDS-PAGE in the second dimension (Görg et al., 1988). The isoelectric focusing (IFF) gel ( $\mathrm{pH}$ gradient 4 -9) was prepared and dried according to the instructions of the manufacturer (Pharmacia) and stored at $-20{ }^{\circ} \mathrm{C}$ until use. Strips $(5 \mathrm{~mm})$ were cut and reswollen in $8 \mathrm{M}$ urea, $0.5 \%$ NP $40,13 \mathrm{mM}$ DT'T and $0.2 \%$ Biolyte $3 / 10$. Whole cells $\left(10^{9}\right)$ were added to $1 \mathrm{ml}$ solubilizing $\operatorname{mix}(9 \mathrm{M}$ urea, $2 \%$ NP-40, $65 \mathrm{mM}$ DTT and $0.8 \%$ Biolyte $3 / 10$ ) and $50 \mu \mathrm{l}$ was applied to the IEF gel strips with the dry strip kit (Pharmacia). After electrophoresis $(30 \mathrm{~min} 150 \mathrm{~V}, 60 \mathrm{~min} 300 \mathrm{~V}, 60 \mathrm{~min}$ $1500 \mathrm{~V}, 30 \mathrm{~min} 2500 \mathrm{~V}, 3 \mathrm{~h} 3000 \mathrm{~V}, 2 \mathrm{~h} 3500 \mathrm{~V} ; 0.05 \mathrm{~mA}$ per strip) the strips were stored at $-70^{\circ} \mathrm{C}$ until use for SDSPACit. The SDS-polyacrylamide gels were prepared with $4 \%$ C, 12-15\% T according to Laemmli (1970). Gels were stained with silver by the method of Blum et al. (1987). Experiments were repeated at least three times. Analysis of the polypeptide pattern was performed visually by two individuals.

Purification of the $\mathbf{4 2} \mathrm{kDa}$ protein from the culture supernatant fluid of PA103. PA103, PA103R and PA103R(pREX18) were grown in cTSB and $30 \mathrm{ml}$ of culture supernatant fluids were diluted $1: 4$ with ice-cold distilled $\mathrm{H}_{2} \mathrm{O}$. DEAE-Sephacel (Pharmacia) (20 g) was swollen with $0.02 \mathrm{M}$ Tris $/ \mathrm{HCl} \mathrm{pH} 7 \cdot 8$, $0 \cdot(11 \mathrm{M} \mathrm{NaCl}$ and added to each dilution and rotated for $2 \mathrm{~h}$ at $4{ }^{\circ} \mathrm{C}$. The material was then packed in a column and washed with $0.02 \mathrm{M}$ Tris/ $\mathrm{HCl}, 0.01 \mathrm{M} \mathrm{NaCl}, \mathrm{pH} 7 \cdot 8$. The pass-through fraction was pooled, and the column eluted with increasing $\mathrm{NaCl}$ concentrations $(0.05 \mathrm{M}, 0.1 \mathrm{M}, 0.15 \mathrm{M}, 0.2 \mathrm{M}, 0.25 \mathrm{M}$, $1 \mathrm{M}$, each in $0.02 \mathrm{M}$ Tris $/ \mathrm{HCl}, \mathrm{pH} 7 \cdot 8$ ). All fractions were pooled, concentrated $(10 \times)$ by ultrafiltration $(10 \mathrm{kDa}$-Unit, Amicon) and subjected to SDS-PAGE. RRP was detected only in the pass-through fractions of PA103 and PA103R(pREX18). The pass-through fraction from the DEAE-Sepharose column was dialysed against $0 \cdot 02 \mathrm{M}$ sodium phosphate buffer, $\mathrm{pH} 7 \cdot 8$, and subjected to Hiload S-Sepharose column (Pharmacia) equilibrated with $0 \cdot 01 \mathrm{M} \mathrm{NaCl}, 0 \cdot 02 \mathrm{M}$ sodium phosphate buffer pll 7.8. Proteins were eluted with increasing $\mathrm{NaCl}$ concentrations $(0.1 \mathrm{M}, 0.25 \mathrm{M}, 0.5 \mathrm{M}, 1 \mathrm{M}$, in $0.02 \mathrm{M}$ phosphate buffer $\mathrm{pH} 7.8$ ). Fractions were pooled, concentrated and analysed by SDS-PAGE. In the $0.25 \mathrm{M}$ fraction a $42 \mathrm{kDa}$ protein (RRP) was detected in PA103 and PA103R(pREX18) but not in PA103R.

In a second purification procedure, $30 \mathrm{ml}$ of the culture supernatant fluids were dialysed against $0.01 \mathrm{M} \mathrm{NaCl}, 0.02 \mathrm{M}$ phosphate buffer $\mathrm{pH} 7 \cdot 8$, and directly applied to the equilibrated $\mathrm{S}$-Sepharose column. Again, RRP was present in the $0.25 \mathrm{M}$ NaCl fraction from PA103R(pREX18) but not from PA103. The RRP fraction was separated by SDS-PAGE (10\% T, $2.6 \%$ $C$ ) and transferred to Immobilon P membrane (Millipore) by semidry-blotting. The membrane was stained with amido black
(Serva), the $42 \mathrm{kDa}$ protein band cut out and the $\mathrm{N}$-terminal amino acid sequence determined by automated Edman degradation (model $470 \mathrm{~A}$ gas-phase sequencer equipped with a 120 PTH amino acid HPLC analyser).

Functional assays for RRP. For preliminary characterization of RRP in supernatants of PA103, the azocasein assay (Prestigde $e t$ al., 1971), radioimmunoassays for detection of alkaline proteinase (Döring et al., 1982) and elastase (Obernesser \& Döring, 1982), and a cytotoxic assay (Döring \& Müller, 1989) were carried out. Dialysed PA103 and PA103R supernatants were used for the investigation of proteolytic activity in the azocasein assay. For the investigation of cytotoxicity, excess specific antibodies against ExoA were added to the supernatants and preincubated for $1 \mathrm{~h}$ at $37^{\circ} \mathrm{C}$. In order to investigate an enhancing effect of RRP on ExoA, purified ExoA equivalent to the concentration of ExoA in PA103 was added to the supernatant of PA103R and cytotoxicity assessed in the $\mathrm{CHO}$ cell assay.

\section{RESULTS}

\section{Construction of the RegA mutant PA103R by insertional mutagenesis of Pseudomonas aeruginosa PA103}

The chromosomal gene $\operatorname{reg} A$ from $P$. aeruginosa PA103 was interrupted by homologous recombination. The integration of plasmid pBRMOB-RegA into $\operatorname{reg} A$ in the $P$. aeruginosa transconjugant $\mathrm{PA} 103 \mathrm{R}$ was confirmed by filter hybridization of chromosomal DNA digested with $X b o I$ (data not shown). Since there is no XhoI restriction site within the coding region of $\operatorname{reg} A$, integration of the plasmid leads to an increase in the size of the $\operatorname{reg} A$-specific fragment by $6.5 \mathrm{~kb}$ (the size of the plasmid). Evidence that pBRMOB-RegA had only integrated in $\operatorname{reg} A$ was shown by the presence of a single hybridizing band. The mutation was complemented by introduction of the plasmid pREX18, carrying $\operatorname{reg} A$, and resulted in strain PA103R(pREX18).

\section{Effect of regA on growth of Pseudomonas aeruginosa}

No differences in doubling time or cell density in the stationary phase were seen between PA103, PA103R and PA103R(pREX18), indicating that $\operatorname{reg} A$ has no influence on bacterial growth. When the iron-depleted medium (cTSB) was supplemented with iron, the cultures reached a higher cell density at stationary phase, indicating that cTSB was iron-limited (Table 2).

\section{Effect of iron and regA on ExoA synthesis in Pseudomonas aeruginosa}

ExoA concentration was determined by radioimmunoassay in the culture supernatant fluids of strains PA103, PA103R and PA103R(pREX18) after growth in cTSB with and without added iron. As expected, ExoA production decreased significantly when iron was added to the iron-depleted medium. The interruption of $\operatorname{reg} A$ in PA103R resulted in an ExoA repression to $1.6 \%$ of the wild-type level. Addition of iron to the medium led to a 
Table 2. Cell density and ExoA synthesis of $P$. aeruginosa PA103, PA103R and PA103R(pREX18)

All values shown represent the mean and SD of at least three experiments with bacteria grown on different davs.

\begin{tabular}{|c|c|c|c|c|}
\hline \multirow[t]{2}{*}{ Strain } & \multicolumn{2}{|c|}{$\mathrm{OD}_{480}$ (stationary phase)* } & \multicolumn{2}{|c|}{$\operatorname{ExoA} \nmid\left(\mu \mathrm{g} \mathrm{ml}^{-1}\right)$} \\
\hline & Low iron & High iron & Low iron & High iron \\
\hline$P \wedge 103$ & $8 \cdot 18 \pm 0.53$ & $18 \cdot 1 \pm 0 \cdot 8$ & $21 \pm 2 \cdot 9$ & $3 \cdot 7 \pm 0 \cdot 91$ \\
\hline PA103R & $8 \cdot 03 \pm 0 \cdot 86$ & $18 \cdot 8 \pm 1 \cdot 2$ & $0 \cdot 4 \pm 0 \cdot 1$ & $0 \cdot 2 \pm 0 \cdot 04$ \\
\hline PA103R(pREX18) & $7 \cdot 86 \pm 0.57$ & $18 \cdot 2 \pm 1 \cdot 4$ & $22 \pm 4 \cdot 3$ & $3.8 \pm 0.98$ \\
\hline
\end{tabular}

* Cells were grown in cTSB to stationary phase (12 h) with no added iron (low iron) or $45 \mu \mathrm{M} \mathrm{FeSO}_{4}$ (high iron). ( $) D_{4 \times 0}=1$ corresponds to $1.5 \times 10^{9}$ c.f.u. $\mathrm{ml}^{-1}$.

f Exod in the culture supernatant fluids was determined by radioimmunoassay after growth of the cells to stationary phase.

(a)

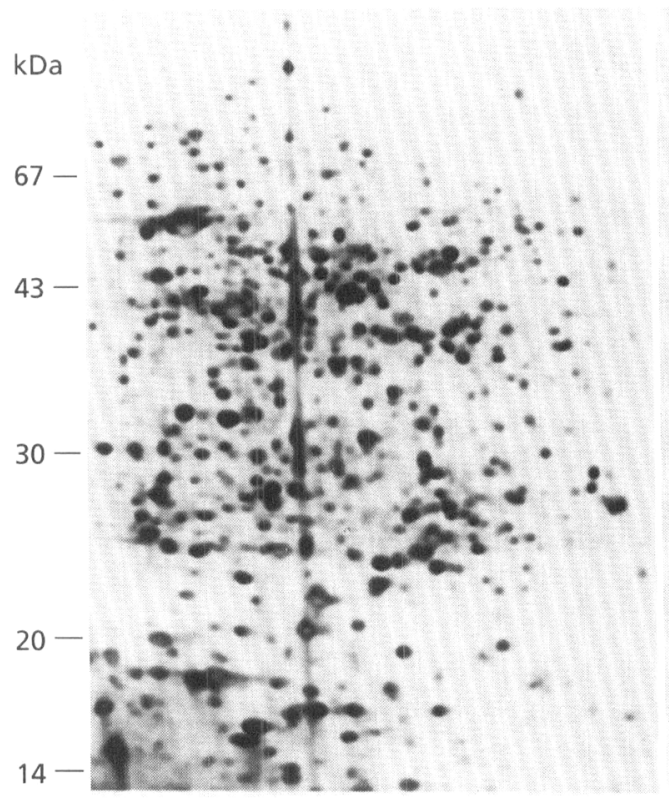

(b)

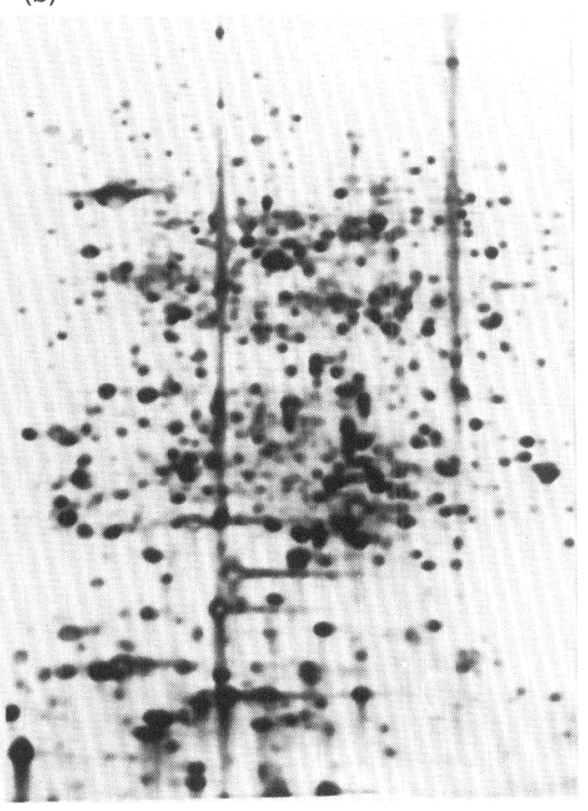

Fig. 1. Two-dimensional electrophoresis of whole cell proteins from $P$. aeruginosa PA103R (a) and PA103R(pREX18) (b) after growth in CTSB. The isoelectric focusing gel in the first dimension contained a pH gradient of 4-9.

slight further reduction in ExoA synthesis in PA103R, but this inhibition was less than the $83 \%$ decrease of ExoA caused by the addition of iron to PA103. The complementation of the $\operatorname{reg} A$ mutation in PA103R(pREX18) restored iron-regulated ExoA synthesis to a degree comparable to PA103 (Table 2).

\section{Effect of regA on the protein patterns of whole Pseudomonas aeruginosa cells}

Extracts from whole cells were subjected to SDS-PAGE and the protein patterns of PA103 and PA103R were compared. Addition of iron in CTSB resulted in differences in the protein pattern compared to the iron-depleted medium. However, no difference between PA103 and PA103R was seen under either growth condition. Twodimensional electrophoresis was used to get a better resolution of the complex protein pattern of whole cells. Approximately 600 polypeptides could be visualized by this technique. Typical gels of proteins from PA103R and PA103R(pREX18) are shown in Fig. 1. The analysis of three independent sets of experiments did not reveal significant differences between the strains. Although spot density may differ from gel to gel due to irregular staining, spots missing in PA103R, but present in PA103 or PA103R(pREX18) and vice versa were not detectable. 


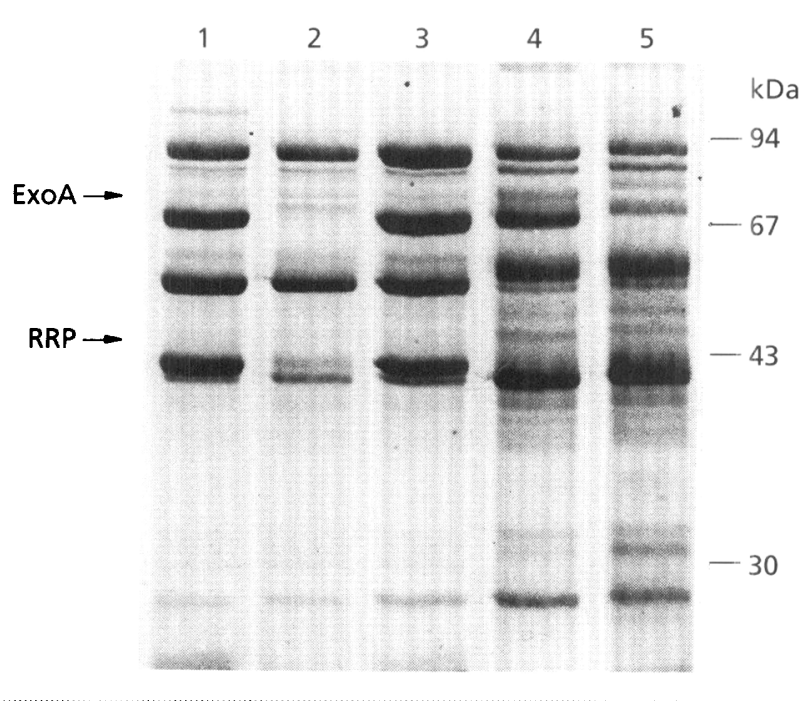

Fig. 2. SDS-PAGE (Coomassie blue stain) of culture supernatant proteins from $P$. aeruginosa strains grown in CTSB without iron (lanes 1, 2 and 3) or with $45 \mu \mathrm{M} \mathrm{FeSO}_{4}$ (lanes 4 and 5). Lanes 1 and 4, PA103; lanes 2 and 5, PA103R; lane 3, PA103R(pREX18).

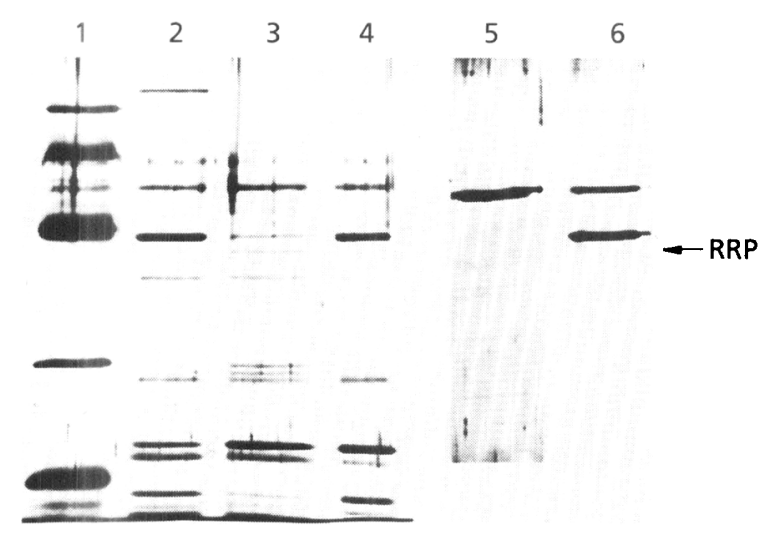

Fig. 3. Purification of the regA-regulated protein (RRP) analysed by SDS-PAGE (silver staining). Lane 1, molecular mass markers (Pharmacia: 94, 67, 43, 30, $20 \mathrm{kDa}$ ); lanes 2, 3 and 4, pass-through fraction after DEAE-Sephacel chromatography; lanes 5 and 6 , eluate from Hiload S-Sepharose column with $0.25 \mathrm{M} \mathrm{NaCl}, 0.02 \mathrm{M}$ phosphate buffer, $\mathrm{pH} 7.8$; lanes 2 and 6 , PA103; lanes 3 and 5, PA103R; lane 4, PA103R(pREX18).

Thus, we did not find cell-associated proteins which are regulated by $\operatorname{reg} A$. In contrast, there were 69 spots (data not shown) detectable in PA103 as well as in PA103R, which were dependent on the iron concentration in the medium.

\section{Effect of regA on proteins of culture supernatant fluids}

Analysis of the secreted proteins in the culture supernatant fluids showed that the total amount of secreted protein was lower under high iron conditions taking into consideration that the final cell density is higher under these conditions. reg $A$ had no effect on alkaline proteinase, since this proteinase was present in equal amounts in the supernatants of PA103 and PA103R. Elastase was not detectable in either supernatant. However, $\operatorname{reg} A$ mutagenesis in $P$. aeruginosa PAO1 revealed no difference in elastase concentrations between PAO1 and its RegAdeficient mutant (data not shown).

Interestingly, the $\operatorname{reg} A$ mutant PA103R was deficient in one prominent negatively iron-regulated protein compared to PA103 and PA103R(pREX18) (Fig. 2). Since this $42 \mathrm{kDa}$ protein did not react with ExoA-specific polyclonal antibodies in immunoblotting it was regarded as a second regA-regulated protein besides ExoA and was named RRP. RRP had no proteolytic activity as shown by the azocasein assay. Experiments in the absence and presence of specific antibodies against ExoA revealed that RRP had no cytotoxic activity (data not shown). Furthermore, addition of purified ExoA to culture supernatants of PA103R in concentrations found in PA103 revealed no significant difference in cytotoxic activity compared to PA103 supernatant. Thus, we conclude that RRP has no ExoA enhancing activity.

\section{Purification and $\mathbf{N}$-terminal sequence of RRP}

Since RRP could not be identified by comparison with secreted proteins described in the literature, the protein was purified and its $\mathrm{N}$-terminal sequence determined. For purification, culture supernatant fluids of PA103, PA103R and PA103R(pREX18) were subjected to ion-exchange chromatography. All steps were done in parallel and each purification step was controlled by comparing protein fractions of PA103, PA103R and PA103R(pREX18) by SDS-PAGE (Fig. 3). The protein passed through the anion exchanger (DEAE-Sephacel) at $\mathrm{pH} 7 \cdot 8$, but was bound to the cation exchanger (S-Sepharose) at $\mathrm{pH} 7 \cdot 8$, indicating a relatively basic $\mathrm{pI}$ of the protein. The protein could be eluted from the S-Sepharose column with 0.25 M $\mathrm{NaCl}$. The same procedure performed with the culture supernatant fluid of PA103R revealed no equivalent protein. The $\mathrm{N}$-terminal sequence determined after blotting the protein onto a polyvinylidene difluoride membrane was XXX-Glu-Thr-Ala-Gly-Lys-Leu-Pro-XXXLys-Pro-Ala-Leu-Gly-Pro-Glu. Database analysis revealed no obvious homology to any known protein sequence (SwissProt release 23, NBRF-PIR release 33, EMBL 32, GenBank 13).

\section{DISCUSSION}

As a tool to study the role of the $\operatorname{reg} A$ gene in $P$. aeruginosa, insertional mutagenesis was used to interrupt the structural gene of $\operatorname{reg} A$. The interruption of the regulatory gene $\operatorname{reg} A$ caused repression of ExoA synthesis to $1.6 \%$ of the wild-type level seen in strain PA103. This is comparable with previous results obtained with the putative reg $A$ mutant PA103-29 (Ohman et al., 1980), which produced $<1 \%$ ExoA compared to PA103. The remaining ExoA synthesis in the mutant PA103R was slightly iron-regulated. This may be due to regulation by 
a Fur analogue since this protein has been detected in $P$. aeruginosa and may bind to the consensus sequence of the Fur binding site at the tox $A$ locus (Prince et al., 1991).

Besides ExoA, another reg $A$-regulated protein (RRP) was detected in the culture supernatant fluid of PA103. Evidence is provided by the following results. First, the protein was not detectable in PA103R, but was present in high concentrations in the culture supernatant of the parental strain PA103 as well as in the trans complementated strain PA103R(pREX18). Second, the synthesis of this protein was strongly negatively iron-regulated and RRP was not detectable in $P$. aeruginosa PAO1 (data not shown), which also produces less ExoA.

RRP is not a fragment of ExoA since polyclonal antibodies against ExoA did not cross-react with this protein. Furthermore the $\mathrm{N}$-terminal sequence of RRP showed no homology with the ExoA sequence. T'he nature of this protein remains unclear since database analysis gave no indication of sequence homology to other proteins. A preliminary characterization of RRP revealed that this protein had no proteolytic, or cytotoxic activity. Furthermore, it did not enhance ExoA activity on $\mathrm{CHO}$ cells.

A $43 \mathrm{kDa}$ protein was described by Ohman et al. (1980) in the supernatant of PA103 which was undetectable in a regA mutant PA103-29. This protein showed ADPribosyltransferase activity which could be inhibited with antiserum against ExoA and thus was thought to be an Exo A fragment. Most likely, Ohman et al. (1980) copurified RRP together with this ExoA fragment by the gel elution technique. We were also able to detect such an ExoA fragment in the supernatant of PA103. This fragment was detectable only by sensitive immunoblotting with antibodies against ExoA and had a slightly higher molecular mass than RRP.

No effects of $\operatorname{reg} A$ on the expression of other ironregulated proteins were seen when using one- and twodimensional gel electrophoresis. Thus, $\operatorname{reg} A$ does not seem to be a global regulator in $P$. aeruginosa and therefore the effects of iron on cell metabolism are likely to be mediated by other regulatory mechanisms such as the fur gene homologue (Prince et al., 1993) or by other, still unknown, genes. The questions whether $\operatorname{reg} A$ regulates RRP transcription, translation and/or processing have not been addressed in the present study. The results from two-dimensional electrophoresis suggest that RRP does not accumulate in the cytosol of PA103R. Further experiments using specific antibodies to RRP are needed to clarify this and other issues concerning RRP.

\section{ACKNOWLEDGEMENTS}

This study was supported by a grant (Do 249/5) from the Deutsche Forschungsgemeinschaft to R. L. and C.W. and a grant from NIH AI15940 to M. L. V. The authors would like to thank the Chemical laboratory of the Hygiene Institute, Tübingen, for determination of iron by atom absorption, D. Roecklin, Transgene Spa, Strasbourg, France, for technical assistance, Dr A. Görg, Technische Universität München, Freising-Weihenstephan, Germany, for the very helpful advice on two-dimensional electrophoresis and Dr M. Guinand, Lniversity of Lyon, France, for providing rabbit polyclonal antibodies against exotoxin $A$.

\section{REFERENCES}

Bagg, A. \& Neilands, J. B. (1987). Ferric uptake regulation protein acts as a repressor, employing iron(II) as a cofactor to bind the operator of an iron transport opeton in Escherichia coli. Biochemistry 26, 5471-5477.

Bjorn, M., Iglewski, B. H., Sadoff, J. \& Vasil, M. L. (1978). Effect of iron on yields of exotoxin $A$ in cultures of Psendomonas aeruginosa PA103. Infect Immun 19, 785-791.

Bjorn, M. J., Sokol, P. A. \& Iglewski, B. H. (1979). Influence of iron on extracellular products in Pseudomonas aeruginosa cultures. J. Bacteriol 138, 193-200.

Blum, H., Beier, H. \& Gross, H. J. (1987). Improved silver staining of plant proteins, RNA and DNA in polyacrylamide gels. Electrophoresis 8, 93-99.

Bourdenet, S., Vacheron, M.-J., Guinand, M., Michel, G. \& Armengon, F. (1990). Biochemical and immunochemical studies of proteolytic fragments of exotoxin A from Pseudomonas aeruginosa. Eur J Biocbem 192, 379-385.

Döring, G. \& Müller, E. (1989). Different sensitivity of Pseudomonas aeruginosa exotoxin $A$ and diphtheria toxin to enzymes from polymorphonuclear leukocytes. Microb Pathog 6, 287-295.

Döring, G., Obernesser, H. J. \& Botzenhart, K. (1982). Extracellular toxins of Pseudomonas aeruginosa. III. Radioimmunoassay for detection of alkaline protease. Zentralbl Bakteriol Mikrobiol Hyg (.A) 252, 239-247.

Döring, G., Goldstein, W., Röll, A., Schiøtz, P. O., Høiby, N. \& Botzenhart, K. (1985). Role of Pseudomonas aeruginosa exoenzymes in lung infections of patients with cystic fibrosis. Infect Immun 49, 557-562.

Figurski, D. \& Helinski, D. R. (1979). Replication of an origincontaining derivative of plasmid $\mathrm{RK} 2$ dependent on a plasmid function provided in trans. Proc Natl Acad Sci US A 76, 1648-1652.

Frank, D. W. \& Iglewski, B. H. (1988). Kinetics of tox. $A$ and tox $R$ mRNA accumulation in Pseudomonas aeruginosa. $J$ Bacteriol 170, $4477-4483$.

Frank, D. W., Storey, D. G., Hindahl, M. S. \& Iglewski, B. H. (1989), Differential regulation by iron of $\operatorname{reg} A$ and toxA transcript accumulation in Pseudomonas aeruginosa. J Bacteriol 171, 5304-5313.

Hamood, A. N. \& Iglewski, B. H. (1990). Expression of the Pseudomonas aeruginosa regulatory gene (regA) in Escherichia coli. $J$ Bacteriol 172, $589-594$.

Hantke, K. (1984). Cloning of the repressor protein gene of ironregulated systems in Escherichia coli K12. Mol \& Gen Genet 197, $337-341$.

Hedstrom, R. C., Funk, C. R., Kaper, J. B., Pavlovskis, O. R. \& Galloway, D. R. (1986). Cloning of a gene involved in regulation of exotoxin A expression. Infect Immun 51, 37-42.

Hindahl, M. S., Frank, D. W., Hamood, A. \& Iglewski, B. H. (1988). Characterization of a gene that regulates toxin $A$ synthesis in Pseudomonas aeruginosa. Nucleic.Acids Res 16, 5699 and 8752.

Görg, A., Postel, W. \& Günther, S. (1988). 'The current state of twodimensional electrophoresis with immobilized $\mathrm{pH}$-gradients. Electrophoresis 9, 531-546.

Kadurugamuwa, J. L., Anwar, H., Brown, M. R. W., Shand, G. H. \& Ward, K. H. (1987). Media for study of growth kinetics and envelope properties of iron-deprived bacteria. J Clin Microbiol 25, 849-855. 
Laemmli, U. K. (1970). Cleavage of structural proteins during the assembly of the head of bacteriophage T4. Nature 227, 680-685.

Liu, P. V. (1966). The roles of various fractions of Pseudomonas aeruginosia in its pathogenesis. III. Identity of the lethal toxins produced in vitro and in vivo. J Infect Dis 166, 481-489.

Miller, J. F., Mekalanos, J. J. \& Falkow, S. (1989). Coordinate regulation and sensory transduction in the control of bacterial virulence. Science $243,916-922$.

Neuhoff, V., Stamm, R. \& Eibl, J. (1985). Clear background and highly sensitive protein staining with Coomassie blue dyes in polyacrilamide gels: a systematic analysis. Electrophoresis $\mathbf{6}$, $427-448$.

Obernesser, H. J. \& Döring, G. (1982). Extracellular toxins of Pseudomonas aeruginosa. IV. Radioimmunoassay for detection of elastase. Zentralbl Bakteriol Mikrobiol Hyg (A) 252, 248-256.

Ohman, D. E., Sadoff, J. C. \& Iglewski, B. H. (1980). Toxin-deficient mutants of Pseudomonas aeruginosa PA103: isolation and characterization. Infect Immun 28, 899-908.

Prestidge, L., Gage, V. \& Spizizen, J. (1971). Protease activities during the course of sporulation in Bacillus subtilis. J Bacteriol 107, 815-823.

Prince, R. W., Storey, D. G., Vasil, A. I. \& Vasil, M. L. (1991). Regulation of tox $A$ and reg.A by the Escherichia coli fur gene and identification of a Fur homologue in Pseudomonas aeruginosa PA103 and PAO1. Mol Microbiol 5, 2823-2831.

Prince, R. W., Cox, C. D. \& Vasil, M. L. (1993). Coordinate regulation of siderophore and exotoxin A production: molecular cloning and sequencing of the Pseudomonas aeruginosa fur gene. $J$ Bacteriol 175, 2589-2598.

Sambrook, J., Fritsch, E. F. \& Maniatis, T. (1989). Molecular Cloning: a Laboratory Manual, 2nd edn. Cold Spring Harbor, NY: Cold Spring Harbor Laboratory.

Simon, R., Priefer, U. \& Pühler, A. (1983). A broad host range mobilization system for in vivo genetic engineering: transposon mutagenesis in gram negative bacteria. Biotechnology 1, 784-791.

Storey, D. G., Frank, D. W., Farinha, M. A., Kropinski, A. M. \& Iglewski, B. H. (1990). Multiple promoters control the regulation of the Pseudomonas aeruginosa reg $A$ gene. Mol Microbio/ 4, 499-503.

Storey, D. G., Raivio, T. L., Frank, D. W., Wick, M. J., Kaye, S. \& Iglewski, B. H. (1991). Effect of regB on expression from the P1 and P2 promoters of the Pseudomonas aeruginosa reg $A B$ operon. $J$ Bacteriol 173, 6088-6094.

Vasil, M. L., Grant, C. C. R. \& Prince, R. W. (1989). Regulation of exotoxin A synthesis in Pseudomonas aeruginosa: characterization of tox:A-lacZ fusions in wild-type and mutant strains. Mol Microbiol 3, $371-81$.

Wick, M. J., Frank, D. W., Storey, D. G. \& Iglewski, B. H. (1990). Structure, function and regulation of Pseudomonas aeruginosa exotoxin A. Annu Rev Microbiol 44, 335-363.

Received 16 September 1993; revised 11 January 1994; accepted 25 January 1994. 